\title{
PEMULIHAN PSIKOSOSIAL ANAK DENGAN METODE GAMES DAN OUTBOND PADA PASCAGEMPA
}

\author{
Nurin Rochayati ${ }^{1 *}$, Agung Pramunarti ${ }^{2}$, Hj.Mas'ad ${ }^{3}$, M.Zainurrahman ${ }^{4}$, Ardiyanto S.Rasang ${ }^{4}$, \\ Nita Sulmayana ${ }^{4}$, Maulana Ahsan ${ }^{4}$, Inggit Putri ${ }^{4}$, Ernawati ${ }^{4}$, Fatu Nurul Yanti ${ }^{4}$ \\ ${ }^{1 *}$ Program Studi Pendidikan Geografi, Fakultas Keguruan dan IImu Pendidikan, Universitas Muhammadiyah Mataram \\ 2Program Studi Pendidikan Geografi, Fakultas Keguruan dan IImu Pendidikan, Universitas Muhammadiyah Mataram \\ ${ }^{3}$ Program Studi Pendidikan Geografi, Fakultas Keguruan dan IImu Pendidikan, Universitas Muhammadiyah Mataram \\ ${ }^{4}$ Program Studi Pendidikan Geografi, Fakultas Keguruan dan IImu Pendidikan, Universitas Muhammadiyah Mataram \\ ${ }^{*}$ Corresponding author : \\ E-mail : nurinrochayati@gmail.com
}

\section{Diterima 16 November 2018, Disetujui 23 November 2018}

\begin{abstract}
ABSTRAK
Tujuan dari pelaksanaan kegiatan pengabdian masyarakat ini untuk memulihkan psikososial anak yang kena dampak gempa. Pengabdian kepada masyarakat dilaksanakan di dusun Kakol Karang Bangket. Dalam pelaksanaan pemulihan tersebut ada beberapa kegiatan yang sangat menarik. Pemulihan psikologi pada anak sangat penting, karena psikologi anak tidak akan terlarut lama dalam kecemasan dan ketakutan. Sehinggga lebih lanjut, akan mempengaruhi gangguan pada jiwanya. Pemulihan psikososial anak dapat dengan trik sebagai berikut; 1) Meyakinkan pada anak masih ada orang yang mencintai. Anak diberi pengarahan nasihat masih banyak orang yang menyayangi. Anak diajarkan untuk berdoa. 2) Membuat anak tersenyum dengan melakukan kegiatan yang menyenakan misalnya dengan bermain, mendongeng atau pengajian, 3) Tidak perlu menanyangkan hal-hal yang membuat anak trauma lagi. Kegiatan yang dilakukan oleh tim prodi pendidikan geografi (dosen dn Mahasiswa), sangat membantu memulihkan keceriaan anak-anak desa Kakol Karang Bengket. Selama ada gempa desa tersebut belum tersentuh adanya bantuan, jadi anak-anak disana masih merasa cemas dan takut. Dengan adanya tim kami, metode yang dipakai bisa membuat anak ceria lagi. Pertama anak mendengarkan cerita yang lucu-lucu, sehingga tawa mereka terdengar. Kedua peserta diajak kelapangan untuk main game/permainan. Peserta yang menang-berani untuk tampil akan diberi hadiah. Hal ini membuat mereka senang, karena merasa mendapatkan penghargaan. Masyarakat Desa Kakol Karang Bengket sangat berterima kasih anak-anaknya bisa kembali ceria dan gembira. Masyarakat tersebut mengharapkan kehadiran kami setiap hari atau seminggu sekali, sehingga anak-anak anak semangat lagi beraktivitas belajar.
\end{abstract}

Kata kunci : Psikososial anak, Dampak Gempa, Pemulihan Psikologi

\begin{abstract}
The purpose of implementing these community service activities is to restore psychosocial children affected by the earthquake. Community service is carried out in the Kakol Karang Bangket hamlet. In implementing the recovery there are several very interesting activities. Psychological recovery in children is very important, because children's psychology will not dissolve long in anxiety and fear. Until further, it will affect the disturbance in his soul. Psychosocial recovery of children can be done with the following tricks; 1) Convincing children is still someone who loves. Children are given guidance that is still a lot of people who love. Children are taught to pray. 2) Make children smile by doing seductive activities for example by playing, storytelling or recitation, 3) There is no need to question the things that make children traumatized again. The activities carried out by the geography education study program (lecturer and student) were very helpful in restoring the joy of the children of the Kakol Karang Bengket village. During the earthquake the village has not been touched by assistance, so the children there still feel anxious and afraid. With our team, the method used can make children happy again. First the children listen to funny stories, so that their laughter is heard. Both participants were invited to the field to play games / games. Participants who win and dare to appear will be rewarded. This makes them happy, because they feel they get an award. The Kakol Karang Bengket Village Community is very grateful that
\end{abstract}


their children can be cheerful and happy again. The community expects our presence every day or once a week, so that children are more enthusiastic about learning activities.

Keywords : Psychosocial children, Earthquake Impact, Psychological Recovery

\section{PENDAHULUAN}

Nusa Tenggara Barat terletak pada dua lempeng besar yang saling bertabrakan, yaitu lempeng Hindia - Australia di bagian selatan dan lempeng Eurasia dibagian utara. Pergeseran lempeng akan menimbulkan panas, merobek batuan yang menyebabkan cairnya batuan dan timbulnya magma kemudian muncul permukaan sebagai gunung api atau intrusi sepanjang tempat pertumbukan yang dikenal dengan nama subdiksi yang berfungsi sebagai sumber letusan gunung api atau gempa.

Gempa di Pulau Lombok diakibatkan oleh aktivitas sesar naik flores yang memanjang dari NTT sampai Bali di bagian utara dan itu menyusup di bagian sepanjang pulau di Nsa tenggara. Menyusup kebawahnya termasuk menyusup di pulau Lombok. Itulah yang menyebabkan terjadinya gempa 7 SR. hingga senin 6 Agustus 2018 lombok terjadi gempa 170 kali gempa susulan. Gempa berkekuatan $7 \mathrm{SR}$ tanggal 5 Agustus 2018 merupakan tipe II karena telah didahului gempa pendahuluan pada tanggal 29 Juli sebesar 6,4 SR. Gempa dapat terjadi kapan saja tidak dapat diprediksi tergantung pada pergerakan bidang patahan atau lempengan tektoknikdisertai tumbukan yang terjadi anatara patahan dengan daratan.

Dampak gempa menyebabkan yang diraskan oleh masyarakat Lombok. Gempa yang berkekuatan tinggi menyebabkan runtuhnya bangunan secara total. Puing-puing dari bangunan yang runtuh merupakan bahaya utama karena efek turunya benda-benda berat dan besar bisa mematikan manusia. Gempa berkekuatan tinggi mengakibatkan pecahann cermin dan jendela. Saat terjadi gempa bebatuan besar dan bagian tanah yang terdapat di atas tergelincir, akibatnya longsor dan batuan beku bisa menyebabkan kerusakan, misalnya di daerah perbukitan Pusuk, Sembalun. Hal tersebut sebagian contoh dari dampak gempa secara kerusakan fisik.

Gempa mengakibatkan gunjangan kejiwaan seseorang terganggu. Hilangnya keluarga saudara yang dicintai merupakan pukulan terberat untuk jiwanya, akhirnya dapat menyebabkan depresi. Mimpi buruk yang selalu meracuni pikiran mereka; mendengar suara keras sedikit tiba-tiba terberanjat dan lari keluar rumah, suara motor besar, suara pesawat dikira ada gempa. Hal ini tidak hanya dialami oleh orang dewasa, anak-anak juga merasakan merasakan. Lebih parah kejiwaan anak-anak bisa trauma berkepanjangan. Aanak-anak yang mulanya ceria menjadi murung yang mulanya suka bermain menjadi pendiam dan tidak akatif lagi. Trauma anak sangat berpengaruh pada perkembangan kejiwaan. Dampak trauma mental yang dialami anak lebih besar dibanding dengan dampak secara fisik. Anak tidak hanya kehilangan orang tua dan saudara, kehilangan pendidikan, teman, kecerian lingkungan dan komunitas yang paling mencemaskan kehilangan masa depan.

Penanganan trauma seperti hal tersebut memang perlu waktu panjang, untuk pemulihan kejiwaan dari rasa kecemasan trauma. Penangan trauma pada anak dengan metode game dan oubond merupakan solusi yang tepat untuk mengurangi rasa trauma tersebut. Anakanak akan diajak bermain sambil belajar di lapangan untuk mengembalikan keceriaan mereka.

\section{HASIL DAN PEMBAHASAN}

Dusun Kakol Karang Bengket merupakan salah satu dusun yang ada berada di desa Pemenang Timur. Karakteristik dan topografi dusun Kakol Karang Bengket mirip dengan desa Pemenang Timur. Letak dan posisi Desa Pemenang timur dapat dikatakan strategis, hal ini dapat dibuktikan dari salah satu empat desa yang ada di kecamatan Pemenang yang berjarak $+1 \mathrm{~km}$ dari pusat kecamatan Pemenang dan $+9 \mathrm{~km}$ dari pusat pemerintahan Kabupaten Lombok Utara. Desa Pemenang timur tergolong wilayah berikilim tropis dengan temperature $30^{\circ} \mathrm{C}$, sedangkan curah hujan ratarata $1758 \mathrm{~mm}$ pertahun dengan jumlah hujan + 6 bulan setiap tahun secara geografis desa pemenang timur terletak $110^{\circ} 48^{\prime} 55,12^{\prime \prime}$ BT dan terletak $7^{\circ} 02^{\prime} 27,52$ " BT. Secara topografis desa Pemenang timur termasuk dalam kategori wilayah daratan, perbukitan dan daratan rendah dengan ketinggian $50 \mathrm{~m}$ dari permukaan laut. Adapaun secara administrative batas wilayah tersebut (lihat peta) sebagai berikut : 
a. Sebelah utara berbatasan dengan desa Gili Indah

b. Sebelah timur berbatasan desa Sigar Penjalin kecamatan Tanjung

c. Sebelah selatan berbatasan dengan desa lembah Sari kecamatan Batu Layar

d. Sebelah barat berbatasan dengan desa Pemenang Barat Kecamatan Pemenang

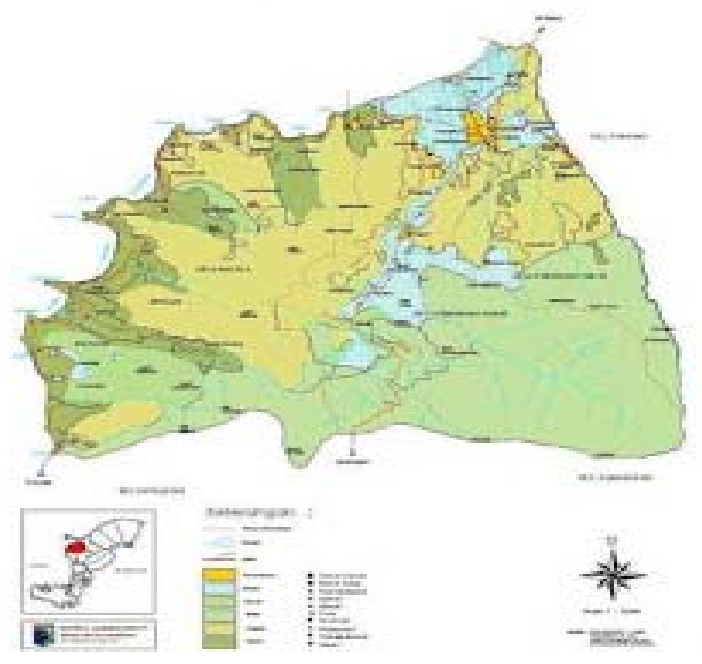

Desa Pemenang mempunyai luas wilayah 12,28 $\mathrm{km}^{2}$, sebagai berikut;

\begin{tabular}{|c|c|c|}
\hline No. & Jenis Kategori & Luas $(\mathrm{H})$ \\
\hline 1 & Tanah sawah & 185 \\
\hline 2 & Irigasi teknis & 145 \\
\hline 3 & $\begin{array}{c}\text { Irigasi setengah } \\
\text { teknisn }\end{array}$ & 40 \\
\hline 4 & Tdah hujan & 130 \\
\hline
\end{tabular}

Tanah bukan sawah dengan luas berjumlah 759

\begin{tabular}{|c|c|c|}
\hline No. & Jenis Kategori & Luas $(\mathrm{H})$ \\
\hline 1 & Perkarangan/bangunan & 185 \\
\hline 2 & Tegalan & 145 \\
\hline 3 & $\begin{array}{c}\text { Lautan, sungai, jalan, } \\
\text { makam }\end{array}$ & 341 \\
\hline
\end{tabular}

Desa Pemenang Timur mempunyai 15 dusun termasuk dusun Kakol Karang Bangket yang ditempati untuk pelaksanaan Pengabdian kepada Masayarakat. Adapun 15 Dusun desa Pemenang Timur sebagai berikut:

1. Dusun Jeliman Ireng

2. Dusun Koloh Tanjung

3. Dusun Kakol Karang Bangket

4. Dusun Tebango

5. Dusun Karang Bedil

6. Dusun Karang Baro
7. Dusun Monton Daya

8. Dusun Karang Monton Lauk

9. Dusun Monton Petak

10. Dusun Terengan Daya

11. Dusun Terengan Tengah

12. Dusun Terengan Timuk

13. Dusun Terengan Lauq

14. DusunTerengan Tanak Ampar

15. Dusun Muara Putat

\section{Demografi}

Penduduk desa Pemenang Timur terus mengalami pertumbuhan dari 2010 sebanyak 7.866 jiwa dan mengalami pertumbuhan sebesar 0,89\% sampai tahun 2014 menjadi sebesar 8.717 jiwa. Data tersebut menunjukan bahwa jumlah penduduk desa Pemenang Timur selama 5 tahun terjadi penambahan 212 jiwa dengan pertumbuhan rata-rata $0,16 \%$. Dengan luas wilayah $12,28 \mathrm{~km}^{2}$ kepadatan penduduk desa pemenang tahun pada tahun 2010 adalah $4,5 \mathrm{~km}^{2}$. Angka tersebut mengalami kenaikan pada akhir tahu 2014 mengalami kenaikan menjadi $5,5 \mathrm{~km}^{2}$ sedang sexratio pemenang penduduk timur tahun 2010 sampai dengan 2014 adalah 90,89\% berarti setiap tahun 95 jiwa penduduk perempuan terdapat 90 jiwa penduduk laki-laki.

Desa Kakol Karang Bengket merupakan desa yang trkena dampak gempa. Bencana gempa yang dirasakan sejak tanggal 29 Juli 2018 sampai sekarang masih merasakanan getaran gempa tersebut. Dampak gempa sungguh sangat dirasakan masyarakat desa Kakol Karang Bengket.hal ini dapat dilihat gambar 01, contoh kerusakan rumah yang rata dengan tanah.

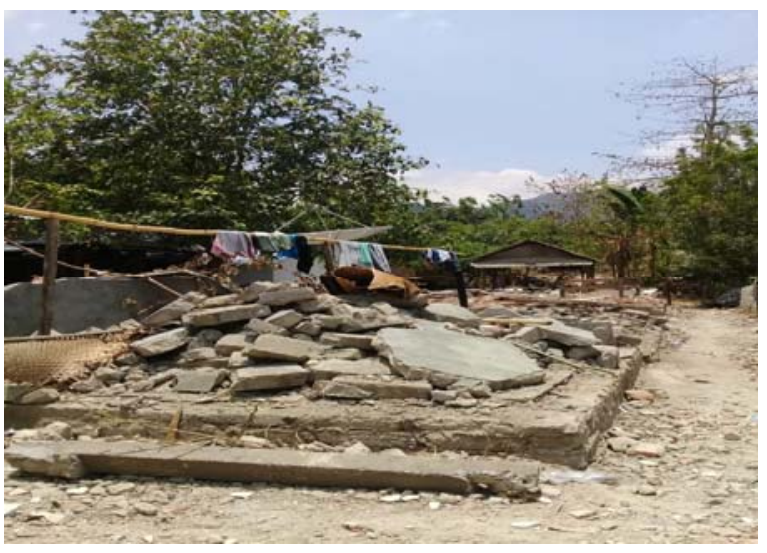

Gambar 1. Kerusakan Rumah. 
Bencana gempa seperti itulah yang membuat masyarakat depresi bahkan anakkecil juga mengalami ketakutan. Reaksi dan respon yang umumnya dialami saat menghadapi bencana antara lain:

1. Merasa cemas, gugup, lebih sensitif dari pada biasanya

2. Terjadinya perubahan pada pola pikir dan perilaku. Biasanya, korban mengingat kembali peristiwa yang telah terjadi meskipun ia tidak menginginkannya (re-experiencing). Hal ini mempengaruhi kondisi fisik (hyper arousal) seperti berkeringat dingin, meningkatnya detak jantung, sulit berkonsentrasi sehingga pola tidur dan makan pun menjadi terganggu.

3. Sensitif terhadap lingkungan sekitar. Suara ribut, getaran atau stimulus lainnya yang memicu ingatan akan bencana menimbulkan kecemasan serta rasa takut akan terulangnya bencana

4. Munculnya gejala fisik yang berkaitan dengan stres (psikosomatis) seperti sakit kepala, sakit dada, insomnia dan lainnya.

Oleh karena itu, pemulihan psikososial anak sangat diperlukan agar tidak terlarut dalam kesedihan dan kecemasan. Pemulihan psikososial anak pasca gempa, akan membantu mencegah gangguan psikologi yang berat. Selain itu pemberin layanan secara intensif perindividu akan membangunankan semangat dan motivasi anak. Psikologi anak akan dapat lebih kuat dalam menghadapai permaslahan yang akan terjadi akan datang, anak akan lebih kuat dan tabah. Memang pemulihan psikososial pada anak ini tidak akan bisa instan langsung sembuh, tetapi akan membutuhkan waktu lama dan ahli psikologi yang handal, kreatif, aktif. AKan tetapi, Tim Pendidikan Geografi (Dosen dan Mahasiswa) untuk berusaha membantu anak-anak di desa tersebut. Kedatangan kami disambut dengan baik oleh bapak kepala dusun Kakol Karang Bengket dan dibalai sudah banyak anak-anak yang wajah yang riang. Dibalik kegembiraan masih ada wajah ketakutan kecemasan Metode dan trik untuk menghilangkan trauma pada anak misalnya, sebagai berikut:

1. Meyakinkan pada anak masih ada orang yang mencintai Anak diberi pengarahan nasihat masih banyak orang yang menyayangi. Anak diajarkan untuk berdoa.

2. Membuat anak tersenyum dengan melakukan kegiatan yang menyenakan misalnya dengan bermain, mendongeng atau pengajian

3. Tidak perlu menanyangakn hal-hal yang membuat anak trauma lagi

Pertama-tama kami memberi icebreaking, mendongeng tentang cerita lucu-lucu pada anak, sehingga anak akan lupa yang dialami. Peserta yang ikut sangat gembira, tertawa bercanda. Sungguh menyenangkan tidak ada rasa kecemasan lagi diwajahnya. Setelah itu instruktur (mahasiswa) memberi game main dan bernyanyii. Anak yang bisa menjawab dan berani untuk tampil ke depan, akan diberi hadiah bola, buku (alat tulis), mainan dan lai-lain. Hail ini merupakan suatu penghargaan pada diri mereka. Peserta sangat antusia apabila ada intstruktur memberi game dan permainan. Lebih lanjut agar permainan/game dan outbond lebih leluasa untuk dilaksanakan, maka peserta diajak ke lapangan yang dekat dengan dusun tersebut. Peserta diajak bermain balapan kelereng, sambil lari. Anak-anak sangat gembira berlarian, tertawa. Kemudian permainan membuat lingkaran, tebak kata. Peserta memperhatikan instruktur, kemudian kalau yang salah kata di hukum menyanyi. Yang benar menebak diberi hadih.

\section{SIMPULAN DAN SARAN Simpiulan}

Pemulihan psikososial pada anak pasca gempa sangat penting, karena agar gangguan psikologi anak tidak berlarut lama. Penanganan dengan mengembalikan keceriaan anak, dibutuhkan waktu yang cukup lama. Akan tetapi kami berusaha untuk mengembalikan semangat dan motivasi anak.anak akan tidak merasa sendiri tidak akan merasa ketakutan dan kecemasan. Kegiatan pemulihan psikososial anak dengan membawa anak untuk tertawa, misalnya dengan bercerita dan mendongeng yang lucu-lucu. Dengan permainan/game tebak kata, lomba balapan kelereng, lomba dengan pegang balon, dan lain-lain. Anak akan lebih ceria dan lebih berani. Pemulihan psikososial sebagai pembentukan jiwa pada anak agar mampu bertahan menghadapi permasalahan dan anak akan lebih kuat menghadapi segala yang menimpa pada dirinya, 
Saran

Kegiatan psikososial diharapkan tidak hanya dilaksanakan sebentar dalam waktu 1 minggu, akan tetapi harus diadakan secara kontinyu. Penangan psikososial anak, masih kurang terpenuhi seluruh pelosok wilayahlombok utara. Kenyataanya di desa Kakol Karang Bengket, jarang dapat bantuan juga.

\section{DAFTAR RUJUKAN}

Crain, William. 2007.Teori PErkembangan, Konsep dan Aplikasi: Pustaka Pelajar

Jahja, Yudrik. 2011.Psikologi perkembangan. Jakarta: Kencana Media Group:

Jesica Malai. PEntinya Pemulihan Trauma PAda Anak Pasca gempa. Diakses pada tanggal $18 \quad$ November 2018. www.komposianan.com

L. Zulkipli.2008. Psikologi Perkembangan. Bandung Remaja Karya CV..

Rizqi, Silvia Amalia. Psikososial. Diakses pada tanggal 18 November 2018. www.komposianan.com 